\title{
C5a stimulates the proliferation of breast cancer cells via Akt-dependent RGC-32 gene activation
}

\author{
$\mathrm{YI} \mathrm{LU}^{1 *}$ and XIAO-BO $\mathrm{HU}^{2 *}$ \\ ${ }^{1}$ Department of General Surgery, Suzhou Kowloon Hospital Affiliated with Shanghai Jiao Tong University \\ School of Medicine, Suzhou, Jiangsu 215021; ${ }^{2}$ Department of Breast Surgery, The Affiliated Tumor Hospital \\ of Xiangya School of Medicine, Central South University, Changsha, Hunan 410013, P.R. China
}

Received May 9, 2014; Accepted August 14, 2014

DOI: $10.3892 /$ or.2014.3489

\begin{abstract}
Complement system activation contributes to various immune and inflammatory diseases, as well as cancers. However, the role of complement activation in the proliferation of cancer cells is not clear. In the present study, we investigated the consequences of complement activation on the proliferation of breast cancer cells and its possible mechanisms. We focused our study on the potential roles of the anaphylatoxins $\mathrm{C} 3 \mathrm{a}$ and $\mathrm{C} 5 \mathrm{a}$ in the proliferation of human breast cancer, as two important immune mediators generated after complement activation. Our study revealed that C5a stimulation, but not $\mathrm{C} 3 \mathrm{a}$, enhanced the proliferation of human breast cancer cells in vitro. Moreover, the expression of response gene to complement 32 (RGC-32) was pronounced in breast cancer cells in response to C5a stimulation. Notably, blockade of the C5a receptor markedly reduced the expression of RGC-32 and the proliferation of breast cancer cells stimulated by C5a. Meanwhile, silencing of RGC-32 expression reduced the proliferation of breast cancer cells induced by C5a treatment. Further investigation revealed that Akt activation was involved in C5a-induced RGC-32 expression and breast cancer cell proliferation. In conclusion, the present study indicates that C5a may promote the proliferation of breast cancer cells through Akt1 activation of the RGC-32 gene.
\end{abstract}

\section{Introduction}

It is well established that the human complement system is a central part of the innate immune response. Complement is known to play a major role as a first defense against microbes $(1,2)$, and also participates in diverse physiological

Correspondence to: $\mathrm{Dr}$ Xiao-Bo Hu, Department of Breast Surgery, The Affiliated Tumor Hospital of Xiangya School of Medicine, Central South University, 283 Tongzipo Road, Changsha, Hunan 410013, P.R. China

E-mail: huxiaobocsu@163.com

*Contributed equally

Key words: breast cancer, C5a, response gene to complement 32, Akt, proliferation processes and contributes to various immune and inflammatory diseases (3-6). There are three conventional mechanisms of complement activation, known as the classical, lectin and alternative pathways $(7,8)$. Activation of complement causes recruitment of immune cells; opsonization of coated cells; and direct killing of affected cells through a membrane attack complex (MAC). During complement activation, soluble proinflammatory peptide fragments $\mathrm{C} 3 \mathrm{a}$ and $\mathrm{C} 5 \mathrm{a}$ are released from C3 and C5 molecules, respectively. C3a and C5a are referred to as anaphylatoxins and exhibit a variety of biological activities in the immune response (9-11).

There is increasing evidence for the contribution of complement activation to cancer progression $(12,13)$. During carcinogenesis, tumor cells acquire genetic and epigenetic alterations that promote their malignant growth. As a result, the complement system can recognize these tumor cells. For decades, complement has been recognized as an effector arm of the immune system that contributes to the destruction of tumor cells $(14,15)$; however, cancer cells can resist the harmful effects of complement by different extracellular and intracellular mechanisms. In fact, new findings on the contribution of complement to tumor growth have challenged the paradigm that complement always protects against tumors. For example, some studies have revealed that the generation of anaphylatoxins $\mathrm{C} 3 \mathrm{a}$ and $\mathrm{C} 5 \mathrm{a}$ in the tumor microenvironment leads to significant tumor progression $(12,13,16,17)$. Nevertheless, the precise roles of $\mathrm{C} 3 \mathrm{a}$ and $\mathrm{C} 5 \mathrm{a}$ in human breast cancer are still controversial.

Response gene to complement 32 (RGC-32) is a novel gene whose expression is induced by complement (18-20). The RGC-32 gene is abundantly expressed in the placenta, skeletal muscle, kidney and liver. Upregulation of RGC-32 gene expression has been demonstrated in a wide range of cell lines in response to a variety of stimuli, such as sublytic C5b-9, steroid hormones and growth factors $(18,19,21)$. It has been reported that RGC-32 plays an important role in cellular proliferation and differentiation $(18,22)$, particularly in human pancreatic cancer and colon cancer $(21,23)$. Based on these findings, the role of the RGC-32 gene in C5a-induced proliferation of breast cancer cells and its regulation by signaling pathways warrant further investigation.

In the present study, we evaluated the role of $\mathrm{C} 3 \mathrm{a}$ and $\mathrm{C} 5 \mathrm{a}$ in human breast cancer cells. We found that breast cancer cells 
are able to enhance proliferation in response to C5a stimulation compared with non-malignant breast epithelial cells. Blockade of the C5a receptor (C5aR) strongly slowed the proliferation of breast cancer cells exposed to C5a. Further investigation revealed that the upregulation of the RGC-32 gene could contribute to $\mathrm{C} 5 \mathrm{a}$-induced breast cancer cell proliferation. Meanwhile, Akt activation was found to be necessary for C5a-induced RGC-32 expression and breast cancer cell proliferation. These results provide novel information concerning the relationship between complement activation and breast cancer, which may influence the development of future therapeutic strategies.

\section{Materials and methods}

Reagents. Polyclonal antibodies against RGC-32 were purchased from Santa Cruz Biotechnology (Santa Cruz, CA, USA). Monoclonal antibodies against $\beta$-actin were purchased from Cell Signaling Technology (Danvers, MA, USA). HRP-conjugated anti-rabbit IgG and HRP-conjugated anti-mouse IgG antibodies, 20X LumiGLO ${ }^{\circledR}$ reagent and 20X peroxide were purchased from Cell Signaling Technology. RIPA lysis buffer was purchased from Thermo Scientific (Fremont, CA, USA). Tbe Cell Counting Kit-8 (CCK-8) was from Dojindo Laboratories (Kumamoto, Japan). The incision enzymes HindIII and EcoRV as well as T4 DNA ligase were purchased from Fermentas (Burlington, Ontario, Canada). The QIAprep ${ }^{\circledR}$ Spin Miniprep kit was obtained from Qiagen (Hilden, Germany). The mammalian expression vector of pcDNA3.1 and Lipofectamine 2000 were from Invitrogen (Carlsbad, CA, USA). The shRNA expression plasmids of pGPU6/GFP were purchased from GenePharma (Shanghai, China). pGL3-basic vector and the dual luciferase assay system were from Promega (Madison, WI, USA). High Capacity cDNA reverse transcription kits and TaqMan ${ }^{\circledR}$ Fast Advanced Master Mix were obtained from ABI (Foster, CA, USA). Human C3a and C5a were from R\&D Systems (Minneapolis, MN, USA).

Cell culture. Established human malignant breast cancer cell lines (MCF-7 and MDA-MB-231) as well as a human non-malignant breast epithelial cell line (HBL-100) were purchased from the American Tissue Culture Collection (ATCC, Rockville, MD, USA). Cells were cultured in DMEM supplemented with $10 \%$ heat-inactivated fetal bovine serum, penicillin $(100 \mathrm{U} / \mathrm{ml})$ and streptomycin $(100 \mu \mathrm{g} / \mathrm{ml})$. Cells were incubated at $37^{\circ} \mathrm{C}$ in a $5 \% \mathrm{CO}_{2}$ incubator.

Construction of the plasmids. To silence the human RGC-32 gene, different shRNA sequences against RGC-32 mRNA (NM_014059.2) were designed. The expression plasmids of RGC-32 shRNA were then constructed by using the plasmids of pGPU6/GFP. The most effective shRNA expression plasmids against the RGC-32 gene and the corresponding scrambled shRNA expression plasmids as a negative control were chosen for further functional experiments. In addition, pcDNA3.1/RGC-32 was constructed by inserting the ORF of human RGC-32 cDNA (NM_014059.2) into the plasmids of pcDNA3.1. The PCAF gene containing an HA tag was amplified by polymerase chain reaction (PCR) from cDNA of normal human breast epithelial cells. The PCR products and the vector of pcDNA3.1 were digested with HindIII and EcoRV, and then ligated by using T4 DNA ligase. Meanwhile, the human RGC-32 promoter (-1600 nt $\sim-1$ nt before ATG) was constructed into the pGL3-basic vector.

Cellular transfection. MCF-7 and MDA-MB-231 cell lines were transfected using Lipofectamine 2000 according to the manufacturer's instructions (24).

Luciferase. MCF-7 and MDA-MB-231 cells at $80 \%$ confluency in 96-well plates were transfected with the pGL3-basic vector containing a human RGC-32 promoter driving luciferase, using Lipofectamine 2000. After $36 \mathrm{~h}$ of transfection, the cells were stimulated with C5a for $9 \mathrm{~h}$, and then lysed for luciferase assays using the dual luciferase assay system.

Quantitative reverse transcriptase-PCR. After isolation of total RNA from cells using TRIzol reagent, an equal amount $(2 \mu \mathrm{g})$ of total RNA from each sample was synthesized as a first-strand cDNA using the High Capacity cDNA reverse transcription kits. The cDNA was than amplified using TaqMan ${ }^{\circledR}$ Fast Advanced Master Mix to detect the level of RGC-32 mRNA. The 7300 Real-Time PCR system (ABI) was used for the experiment. The reaction program consisted of an initial denaturation step at $95^{\circ} \mathrm{C}$ for $10 \mathrm{~min}$, denaturation at $95^{\circ} \mathrm{C}$ for $15 \mathrm{sec}$ and annealing at $60^{\circ} \mathrm{C}$ for $60 \mathrm{sec}$ for 40 cycles. The $\beta$-actin gene was used as an internal control. The relative level of gene expression was obtained by calculating the ratio of the cycle numbers of the initial exponential amplification phase as determined by the sequence detection system for RGC-32 and $\beta$-actin using the $2^{-\Delta \Delta \mathrm{Ct}}$ formula. Each sample was assayed in triplicate.

Western blot analysis. The proteins $(40 \mu \mathrm{g})$ were subjected to $12 \%$ SDS polyacrylamide gel electrophoresis and transferred onto PVDF membranes (Millipore, Billerica, MA, USA) by a semi-dry electrophoretic transfer cell (Bio-Rad). The membranes were incubated for $1 \mathrm{~h}$ at room temperature in blocking buffer (5\% skimmed milk in TBS-T), and were then incubated with the antibodies against RGC-32 and $\beta$-actin, respectively, overnight at $4^{\circ} \mathrm{C}$. After washing with TBST-T three times, the membranes were incubated with HRP-conjugated anti-rabbit and anti-mouse antibodies for $1 \mathrm{~h}$ at $37^{\circ} \mathrm{C}$. The bands were then visualized by the ECL detection system (Bio$\mathrm{Rad}$ ) with 3 to $10 \mathrm{~min}$ exposure after washing the membranes. Finally, the radiographic band density was measured using Quantity One software (Bio-Rad). Control for protein loading was verified by using $\beta$-actin as the internal standard. Similar results were obtained in three independent experiments.

CCK- 8 assay. MCF-7, MDA-MB-231 and HBL-100 cells were incubated with CCK-8 for the final $3 \mathrm{~h}$ before detection. The formazan product was then visualized at the absorbance of $450 \mathrm{~nm}$, and the absorbance was directly proportional to the number of living cells $(25,26)$. Each sample was assayed in triplicate.

Statistical analysis. All data are expressed as mean \pm SD. All statistical analysis was carried out using SPSS 11.5 software. 
$\mathbf{A}$

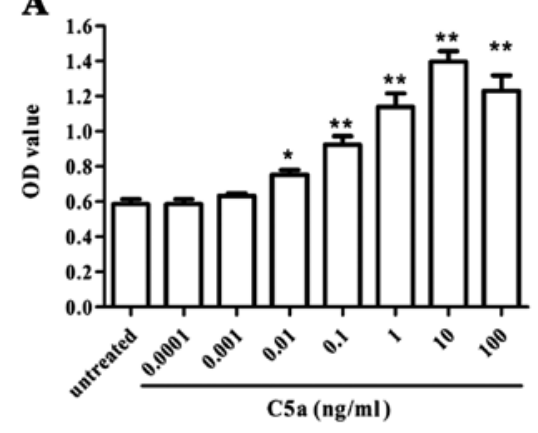

B
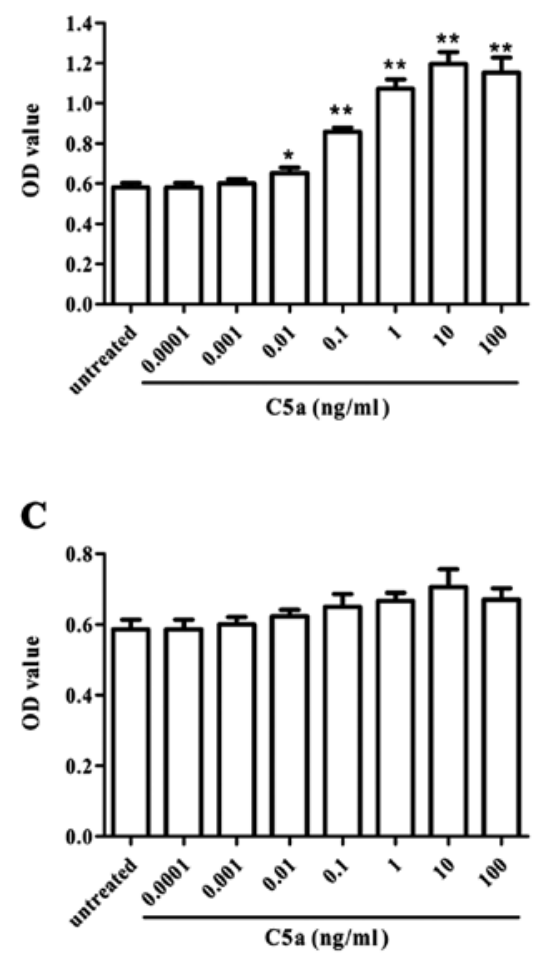

Figure 1. The role of C5a in the proliferation of human breast cancer cell lines. The two human breast cancer cell lines (MCF-7 and MDA-MB-231) and the non-malignant breast epithelial cell line (HBL-100) as a control were cultured in vitro. Purified human C5a was then added to the MCF-7, MDA-MB-231 and HBL-100 cells, respectively, during this time period. CCK-8 assay revealed that $\mathrm{C} 5 \mathrm{a}$ stimulation for $48 \mathrm{~h}$ enhanced the proliferative response of both (A) MCF-7 and (B) MDA-MB-231 cell lines in a dose-dependent manner with a prominent effect at the dose of $10 \mathrm{ng} / \mathrm{ml}$. (C) In contrast, C5a stimulation had no significant effect on the proliferation of the HBL-100 cell line. Results are representative of 3 independent experiments. Data are presented as means $\pm \mathrm{SD} .{ }^{*} \mathrm{P}<0.05 ;{ }^{* *} \mathrm{P}<0.01$ vs. untreated group.

One-way analysis of variance (ANOVA), followed by post hoc Bonferroni test with adjustment for multiple comparisons, was used to test the significance of the differences between groups. A P-value $<0.05$ was considered to indicate a statistically significant difference.

\section{Results}

C5a promotes the proliferation of human breast cancer cells. In order to determine the role of $\mathrm{C} 3 \mathrm{a}$ and $\mathrm{C} 5 \mathrm{a}$ in the proliferation of human breast cancer cells, two human breast cancer cell lines (MCF-7 and MDA-MB-231) and a non-malignant
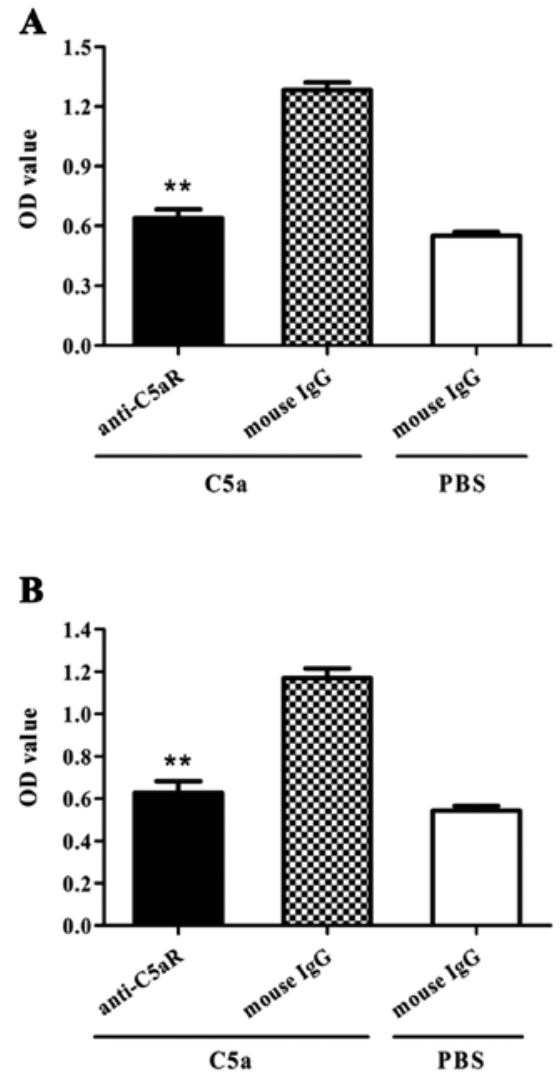

Figure 2. Effects of C5aR blockade on C5a-induced proliferation of breast cancer cell lines. The anti-C5aR neutralizing antibody was added into the medium and cultured for $30 \mathrm{~min}$. C5a was then added into the medium and cultured for $48 \mathrm{~h}$, and the proliferation of breast cancer cells was subsequently detected by the CCK- 8 assay. The results revealed that blockade of C5aR with the anti-C5aR neutralizing antibody markedly reduced the proliferation of (A) MCF-7 and (B) MDA-MB-231 cells exposed to C5a. Results are representative of 3 independent experiments. Data are presented as means $\pm S D$ ${ }^{* *} \mathrm{P}<0.01$ vs. the mouse $\mathrm{IgG}+\mathrm{C} 5$ a group.

breast epithelial cell line (HBL-100) as a control were cultured in vitro. Purified human $\mathrm{C} 3 \mathrm{a}$ and $\mathrm{C} 5 \mathrm{a}$ were then added to the human breast cancer cell lines and the non-malignant breast epithelial cell line, respectively, to evaluate their ability to induce the proliferation of breast cancer cells. The results showed that $\mathrm{C} 5 \mathrm{a}$ stimulation enhanced the proliferative response of both human breast cancer cell lines in vitro, but had no marked effect on the proliferation of the non-malignant breast epithelial cell line (Fig. 1A-C). No significant increase in cellular proliferation in response to $\mathrm{C} 3 \mathrm{a}$ was observed in the breast cancer cell lines MCF-7 and MDA-MB-231 (data not shown).

Blockade of C5aR slows the proliferation of breast cancer cells. Since the breast cancer cell lines showed a significant increase in proliferation in response to C5a stimulation, the influence of C5a on the proliferation of breast cancer cells was further studied using the anti-C5aR neutralizing antibody as a C5aR antagonist. The result revealed that blockade of C5aR with the anti-C5aR neutralizing antibody markedly reduced the proliferation of the two breast cancer cell lines cultured with human C5a (Fig. 2A and B). Taken together, these findings (Figs. 1 and 2) indicate that anaphylatoxin C5a promotes the proliferation of the human breast cancer cell lines. 
A

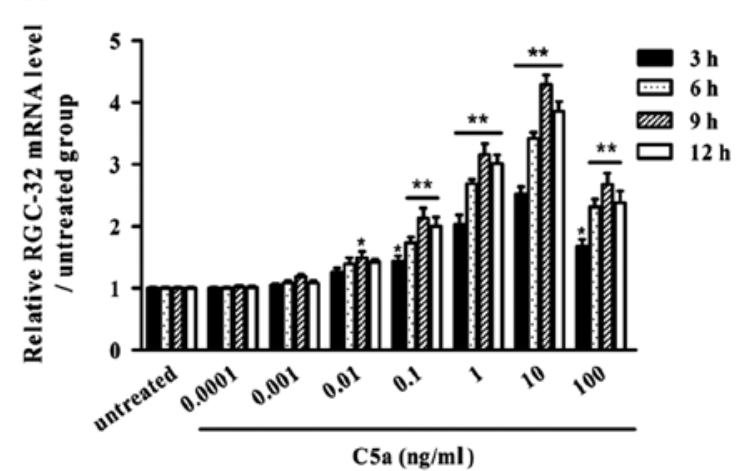

C

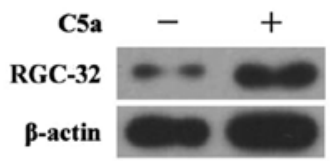

E

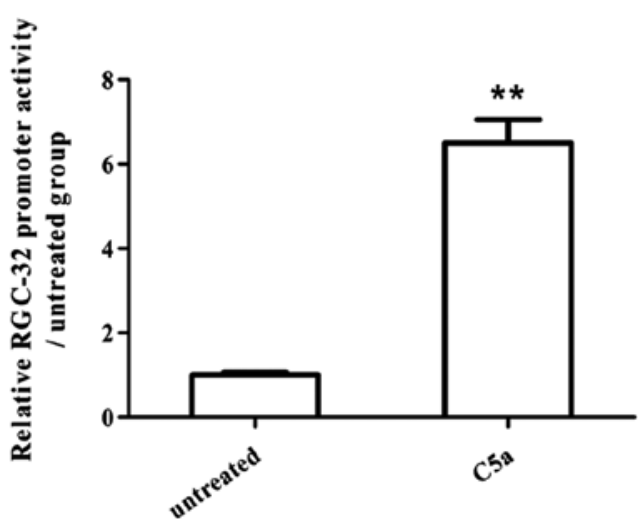

B

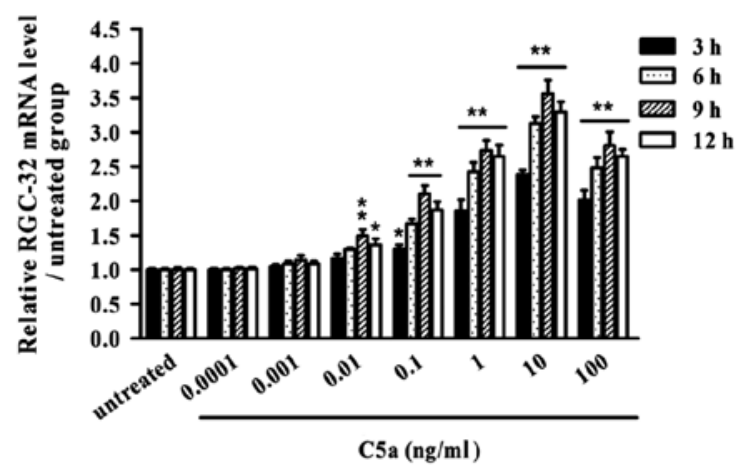

D

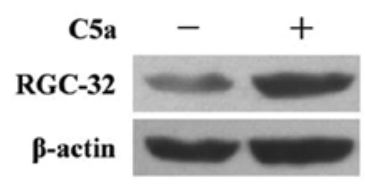

$\mathbf{F}$

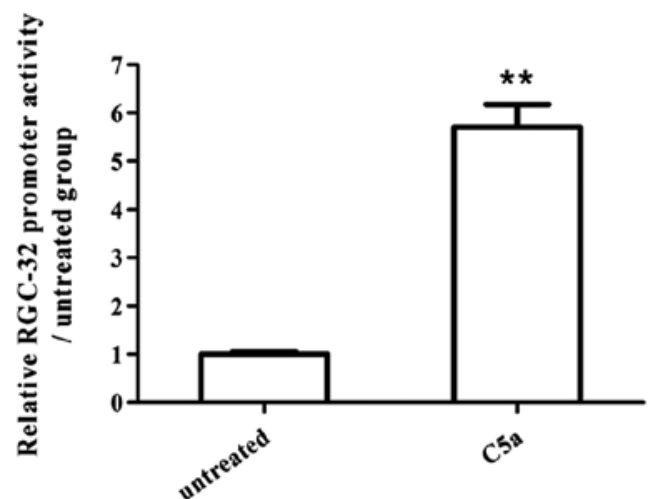

Figure 3. RGC-32 expression in C5a-induced breast cancer cell lines. Expression of the RGC-32 gene was detected in the breast cancer cell lines exposed to C5a. (A and B) Real-time PCR assay showed that the level of RGC-32 mRNA was markedly elevated not only in the (A) MCF-7 cell line but also in the (B) MDA-MB-231 cell line in response to C5a stimulation. (C and D) Western blot analysis showed that the expression of RGC-32 was significantly increased at the protein level in both (C) MCF-7 and (D) MDA-MB-231 cell lines in response to C5a stimulation. (E and F) Luciferase experiments revealed that transcription of the RGC-32 gene was markedly increased in both cell lines including (E) MCF-7 and (F) MDA-MB-231 after stimulation by C5a. Results are representative of 3 independent experiments. Data are presented as means $\pm \mathrm{SD}$. ${ }^{*} \mathrm{P}<0.05 ;{ }^{* *} \mathrm{P}<0.01$ vs. the untreated group.

RGC-32 expression is induced in breast cancer cells exposed to $C 5 a$. It is well accepted that RGC-32 is a novel gene whose expression is induced by complement and other stimuli (18-20). Given that C5a may contribute to the proliferation of breast cancer cells, we further detected the expression of the RGC-32 gene in breast cancer cells exposed to C5a. The results showed that the expression of RGC-32 was markedly elevated in the breast cancer cells in response to C5a stimulation at both the mRNA and protein levels (Fig. 3A-D). The luciferase experiments further demonstrated that transcription of the RGC-32 gene was significantly increased in the breast cancer cells after stimulation by C5a (Fig. 3E and F). These findings indicate that C5a in vitro has the ability to promote RGC-32 gene expression in human breast cancer cell lines.

Expression of $R G C-32$ is required for $C 5 a$-induced proliferation in breast cancer cells. It remains to be determined whether RGC-32 expression is necessary for the proliferation of breast cancer in response to $\mathrm{C} 5 \mathrm{a}$ stimulation. Thus, breast cancer cells were transfected with RGC-32 shRNA-expressing plasmids, and then the cellular proliferation in response to C5a stimulation was determined by the CCK- 8 assay. The results revealed that treatment with RGC-32 shRNA obviously suppressed the proliferation of breast cancer cells in response to C5a stimulation (Fig. 4). Remarkably, overexpression of the RGC-32 gene by plasmids of pcDNA3.1/RGC-32 promoted the proliferation of the breast cancer cells (Fig. 5), indicating that RGC-32 expression is involved in C5a-induced proliferation of breast cancer cells. These findings indicate that $\mathrm{C} 5 \mathrm{a}$-induced RGC-32 expression is required for the proliferation of breast cancer cells.

Akt activation is necessary for C5a-induced RGC-32 expression and breast cancer cell proliferation. Akt is a widely recognized contributory factor in the proliferation of cancer 


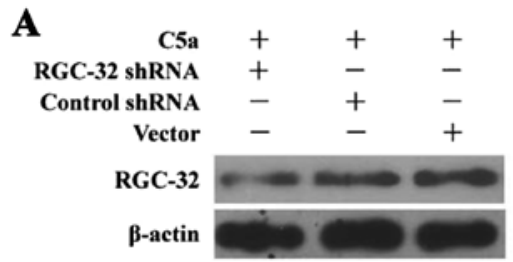

C

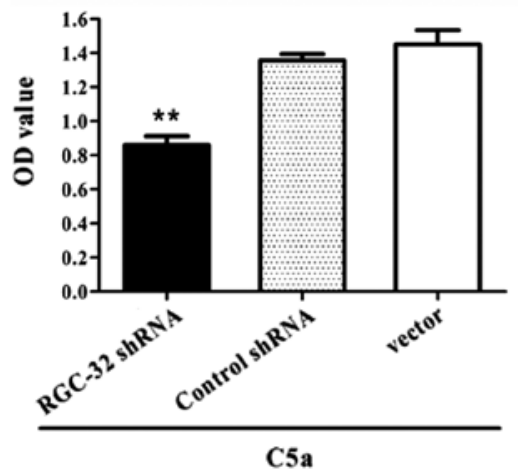

B

\begin{tabular}{|c|c|c|c|}
\hline C5a & + & + & + \\
\hline RGC-32 shRNA & + & - & - \\
\hline Control shRNA & - & + & - \\
\hline Vector & - & - & + \\
\hline RGC-32 & $\infty$ & & \\
\hline$\beta$-actin & & & \\
\hline
\end{tabular}

D

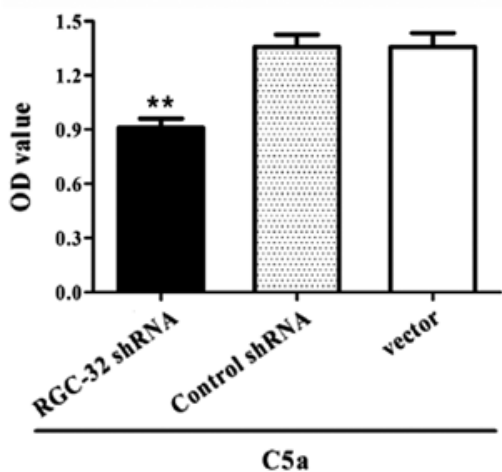

Figure 4. The role of RGC-32 in the proliferation of breast cancer cell lines exposed to C5a. Breast cancer cells were transfected with RGC-32 shRNA and cultured continually for $48 \mathrm{~h}$, and then C5a was used to stimulate breast cancer cell proliferation. (A and B) Western blot analysis revealed that, in comparison with control shRNA, treatment with RGC-32 shRNA obviously suppressed the expression of RGC-32 in both the (A) MCF-7 and (B) MDA-MB-231 cell lines in response to C5a stimulation. (C and D) In comparison with control shRNA, treatment with RGC-32 shRNA obviously suppressed the proliferation of the (C) MCF-7 and (D) MDA-MB-231 cell lines in response to C5a stimulation as determined by the CCK-8 assay. Results are representative of 3 independent experiments. Data are presented as means $\pm \mathrm{SD}$. ${ }^{* *} \mathrm{P}<0.01$ vs. control shRNA + C5a group and vector + C5a group.

$\mathbf{A}$

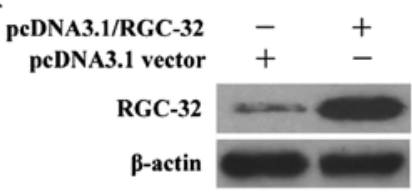

C

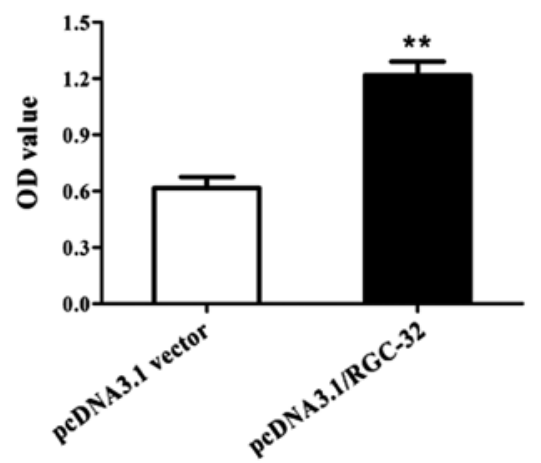

B

\begin{tabular}{rll} 
peDNA3.1/RGC-32 & - & + \\
peDNA3.1 vector & + & - \\
RGC-32 & \\
B-actin & \\
\hline
\end{tabular}

D

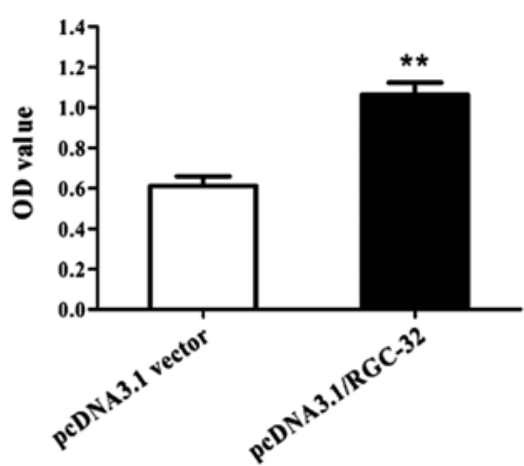

Figure 5. The effects of RGC-32 overexpression on the proliferation of breast cancer cell lines. The plasmids of the pcDNA3.1/RGC-32 and pcDNA3.1 vectora were transfected into the two breast cancer cell lines respectively, and cultured continuously for $48 \mathrm{~h}$. (A and B) Western blot analysis revealed that transfection of pcDNA3.1/RGC-32 increased RGC-32 expression in both the (A) MCF-7 and (B) MDA-MB-231 cell lines. (C and D) CCK-8 assay revealed that overexpression of the RGC-32 gene promoted the proliferation of the (C) MCF-7 and (D) MDA-MB-231 cell lines compared to the pcDNA3.1 vector control group. Results are representative of 3 independent experiments. Data are presented as means $\pm \mathrm{SD}$. ${ }^{* *} \mathrm{P}<0.01$ vs. the pcDNA3.1 vector group.

cells. Since Akt activation has been reported to promote cell proliferation in response to complement stimulation (27-29), and both C5a stimulation and RGC-32 gene expression were involved in the proliferation of breast cancer cells (Fig. 5), the influence of Akt activation on C5a-induced RGC-32 expression and breast cancer cell proliferation was further explored in the present study. The results revealed that inhibition of Akt activation with Ly294002 strongly reduced C5a-induced RGC-32 expression and breast cancer cell proliferation (Fig. 6). It was therefore confirmed that Akt activation contributes to C5a-induced RGC-32 expression and breast cancer cell proliferation. 
$\mathbf{A}$

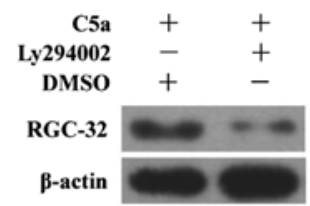

C

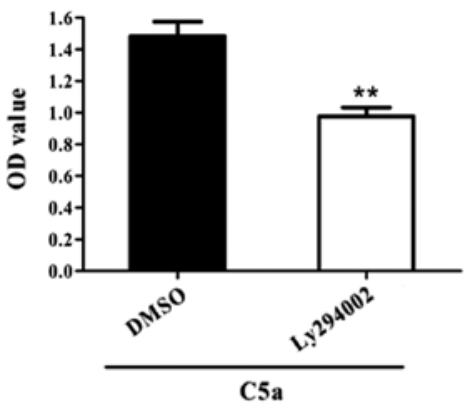

B

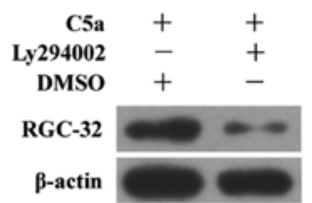

D

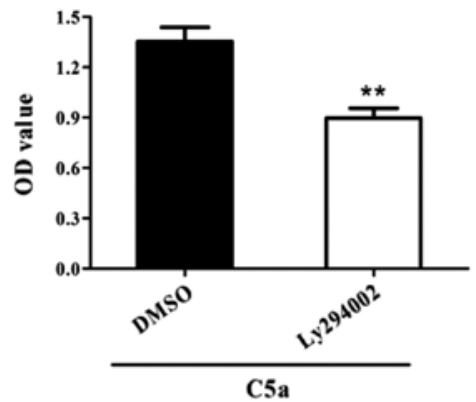

Figure 6. The roles of Akt activation in C5a-induced RGC-32 expression and breast cancer cell proliferation. Ly294002 (25 $\mu \mathrm{M})$ was used to inhibit Akt activation, and then C5a was added to induce RGC-32 expression and breast cancer cell proliferation. (A and B) Western blot analysis revealed that inhibition of Akt activation with Ly294002 significantly reduced C5a-induced RGC-32 expression in both the (A) MCF-7 and (B) MDA-MB-231 cell lines. (C and D) CCK-8 assay revealed that Ly294002 significantly reduced C5a-induced proliferation of the (C) MCF-7 and (D) MDA-MB-231 cell lines. Results are representative of 3 independent experiments. Data are presented as means \pm SD. ${ }^{* *} \mathrm{P}<0.01$ vs. the DMSO + C5a group.

\section{Discussion}

Breast carcinogenesis is a multi-step process in which normal breast cells acquire genetic and epigenetic alterations that result in the expression of many cancer-associated molecules (30-32). However, the mechanism by which breast cancer cells undergo proliferation still remains controversial.

Complement is known to play important roles as a first defense against microbes, and also participates in diverse physiological processes and contributes to various immune and inflammatory diseases $(4,33-35)$. In addition, there is increasing evidence for the contribution of complement activation to cancer progression $(12,16)$. Cancer cells appear to be able to establish a convenient balance between complement activation and inhibition, taking advantage of complement initiation without suffering its deleterious effects. Various studies have demonstrated that generation of anaphylatoxins $\mathrm{C} 3 \mathrm{a}$ and $\mathrm{C} 5 \mathrm{a}$ in the tumor microenvironment leads to significant tumor progression $(12,16,17)$. During the development of tumors, complement $\mathrm{C} 3$ and $\mathrm{C} 5$ activation may support chronic inflammation, promote an immunosuppressive microenvironment, induce angiogenesis, and activate cancer-related signaling pathways. Little is known, however, concerning the roles of C3a and C5a in breast cancer.

In the present study, we provide evidence for the contribution of C5a to the proliferation of breast cancer cells. In particular, we found that breast cancer cells were able to proliferate in response to $\mathrm{C} 5$ a stimulation much more efficiently than non-malignant breast cells, indicating that breast cancer cells are more sensitive to C5a stimulation than nonmalignant breast cells. In contrast, C3a did not significantly affect the proliferation of breast cancer cells. Other effects of $\mathrm{C} 3 \mathrm{a}$ on breast cancer cells need to be determined to explore the potential roles of $\mathrm{C} 3 \mathrm{a}$ in breast cancer.
RGC-32 is a novel gene induced by complement and other stimuli (18-20). It is well known that upregulation of RGC-32 gene expression contributes to the proliferation of target cells $(18,19,21)$. However, the precise role of the RGC-32 gene in C5a-induced proliferation of breast cancer cells needs to be explored. Our present study demonstrated that the expression of RGC-32 was markedly elevated in breast cancer cells in response to C5a stimulation. Further investigation revealed that gene transfer of RGC-32 shRNA obviously diminished the proliferation of breast cancer cells in response to $\mathrm{C} 5 \mathrm{a}$ stimulation. Conversely, overexpression of the RGC-32 gene by transfection of pcDNA3.1/RGC-32 promoted the proliferation of breast cancer cells without C5a stimulation. These findings indicate that C5a-induced RGC-32 expression is required for the proliferation of breast cancer cells.

Further experiments were carried out to discover the possible mechanism by which C5a stimulates the expression of the RGC-32 gene in breast cancer cells. The phosphoinositide 3-kinase (PI3K)/Akt signaling pathway is one of the most frequently dysregulated pathways in human cancers $(36,37)$. On the other hand, Akt activation has been reported to promote cell proliferation in response to complement stimulation (27-29). Thus, in a subsequent experiment, we sought to explore the role of Akt activation in regulating RGC-32 expression and cellular proliferation of breast cancer cells in response to $\mathrm{C5}$ a. The results revealed that inhibition of Akt activation suppressed RGC-32 expression and cellular proliferation of breast cancer cells induced by C5a. Further studies need to be performed to discover the possible regulatory mechanism by which Akt increases the expression of the RGC-32 gene in breast cancer cells.

In conclusion, we evaluated the roles of $\mathrm{C} 3 \mathrm{a}$ and $\mathrm{C} 5 \mathrm{a}$ in promoting the proliferation of breast cancer cells in vitro. We found that breast cancer cells are able to undergo proliferation 
in response to $\mathrm{C} 5 \mathrm{a}$ stimulation rather than $\mathrm{C} 3 \mathrm{a}$. We also found a significant increase in the expression of the RGC-32 gene in breast cancer cells induced by C5a. Further investigation revealed that upregulation of the RGC-32 gene could contribute to C5a-induced proliferation of breast cancer cells. Finally, Akt activation was shown to be necessary for C5a-induced RGC-32 expression and breast cancer cell proliferation. On the basis of these observations, we conclude that $\mathrm{C} 5 \mathrm{a}$ promotes the proliferation of breast cancer cells through Akt-activated RGC-32 gene expression. These findings provide novel information concerning the relationship between complement activation and breast cancer, which may influence the development of future therapeutic strategies.

\section{References}

1. Tong HH, Lambert G, Li YX, et al: Deletion of the complement C5a receptor alleviates the severity of acute pneumococcal otitis media following influenza A virus infection in mice. PloS One 9 e95160, 2014

2. Courtois A, Berthou C, Guezennec J, Boisset C and Bordron A: Exopolysaccharides isolated from hydrothermal vent bacteria can modulate the complement system. PloS One 9: e94965, 2014.

3. Wende E, Laudeley R, Bleich A, et al: The complement anaphylatoxin $\mathrm{C} 3 \mathrm{a}$ receptor $(\mathrm{C} 3 \mathrm{aR})$ contributes to the inflammatory response in dextran sulfate sodium (DSS)-induced colitis in mice. PloS One 8: e62257, 2013.

4. Elvington M, Blichmann P, Qiao F, et al: A novel protocol allowing oral delivery of a protein complement inhibitor that subsequently targets to inflamed colon mucosa and ameliorates murine colitis. Clin Exp Immunol: 500-508, 2014.

5. Hundgeburth LC, Wunsch M, Rovituso D, et al: The complement system contributes to the pathology of experimental autoimmune encephalomyelitis by triggering demyelination and modifying the antigen-specific T and B cell response. Clin Immunol 146 : $155-164,2013$

6. Laudisi F, Spreafico R, Evrard M, et al: Cutting edge: the NLRP3 inflammasome links complement-mediated inflammation and IL-1 $\beta$ release. J Immunol 191: 1006-1010, 2013.

7. Ma R, Cui Z, Hu SY, et al: The alternative pathway of complement activation may be involved in the renal damage of human anti-glomerular basement membrane disease. PloS One 9: e91250, 2014.

8. Osthoff M, Brown KD, Kong DC, Daniell M and Eisen DP: Activation of the lectin pathway of complement in experimental human keratitis with Pseudomonas aeruginosa. Mol Vis 20 $38-45,2014$

9. Cravedi P, Leventhal J, Lakhani P, Ward SC, Donovan MJ and Heeger PS: Immune cell-derived C3a and C5a costimulate human T cell alloimmunity. Am J Transplant 13: 2530-2539, 2013.

10. van der Touw W, Cravedi P, Kwan WH, Paz-Artal E, Merad M and Heeger PS: Cutting edge: Receptors for C3a and C5a modulate stability of alloantigen-reactive induced regulatory T cells. J Immunol 190: 5921-5925, 2013.

11. Lara-Astiaso D, Izarra A, Estrada JC, et al: Complement anaphylatoxins $\mathrm{C} 3 \mathrm{a}$ and $\mathrm{C} 5 \mathrm{a}$ induce a failing regenerative program in cardiac resident cells. Evidence of a role for cardiac resident stem cells other than cardiomyocyte renewal. Springerplus 1: 63, 2012. doi: 10.1186/2193-1801-1-63.

12. Kanmura S, Uto h, Sato Y, et al: The complement component C3a fragment is a potential biomarker for hepatitis $\mathrm{C}$ virus-related hepatocellular carcinoma. J Gastroenterol 45: 459-467, 2010.

13. Habermann JK, Roblick UJ, Luke BT, et al: Increased serum levels of complement $\mathrm{C} 3 \mathrm{a}$ anaphylatoxin indicate the presence of colorectal tumors. Gastroenterology 131: 1020-1029, 2006.

14. Stecker JR, Savage AA, Bruno JG, Garcia DM and Koke JR: Dynamics and visualization of MCF7 adenocarcinoma cell death by aptamer-Clq-mediated membrane attack. Nucleic Acid Ther 22: 275-282, 2012.

15. Baig NA, Taylor RP, Lindorfer MA, et al: Complement dependent cytotoxicity in chronic lymphocytic leukemia: ofatumumab enhances alemtuzumab complement dependent cytotoxicity and reveals cells resistant to activated complement. Leuk Lymphoma 53: 2218-2227, 2012.
16. Nitta H, Wada Y, Kawano Y, et al: Enhancement of human cancer cell motility and invasiveness by anaphylatoxin C5a via aberrantly expressed C5a receptor (CD88). Clin Cancer Res 19: 2004-2013, 2013.

17. Corrales L, Ajona D, Rafail S, et al: Anaphylatoxin C5a creates a favorable microenvironment for lung cancer progression. J Immunol 189: 4674-4683, 2012.

18. Fosbrink M, Cudrici C, Tegla CA, et al: Response gene to complement 32 is required for C5b-9 induced cell cycle activation in endothelial cells. Exp Mol Pathol 86: 87-94, 2009.

19. Vlaicu SI, Cudrici C, Ito T, et al: Role of response gene to complement 32 in diseases. Arch Immunol Ther Exp 56: 115-122, 2008.

20. Badea TC, Niculescu FI, Soane L, Shin ML and Rus H: Molecular cloning and characterization of RGC-32, a novel gene induced by complement activation in oligodendrocytes. J Biol Chem 273: 26977-26981, 1998.

21. Vlaicu SI, Tegla CA, Cudrici CD, et al: Epigenetic modifications induced by RGC-32 in colon cancer. Exp Mol Pathol 88: 67-76, 2010.

22. Li F, Luo Z, Huang W, et al: Response gene to complement 32 , a novel regulator for transforming growth factor-beta-induced smooth muscle differentiation of neural crest cells. J Biol Chem 282: 10133-10137, 2007.

23. Zhu L, Qin H, Li PY, et al: Response gene to complement-32 enhances metastatic phenotype by mediating transforming growth factor beta-induced epithelial-mesenchymal transition in human pancreatic cancer cell line BxPC-3. J Exp Clin Cancer Res 31: 29, 2012

24. Yunus MA, Chung LM, Chaudhry Y, Bailey D and Goodfellow I: Development of an optimized RNA-based murine norovirus reverse genetics system. J Virol Methods 169: 112-118, 2010.

25. Li M, Han S, Zhang G, Wang Y and Ji Z: Antiproliferative activity and apoptosis-inducing mechanism of L-securinine on human breast cancer MCF-7 cells. Pharmazie 69: 217-223, 2014.

26. Gong S, Tao Z, Liu X and Gan L: An underlying prognosis predictor of hepatocellular carcinoma: Oncoprotein 18. Biomed Rep 2: 85-88, 2014.

27. Qiu W, Zhang Y, Liu X, et al: Sublytic C5b-9 complexes induce proliferative changes of glomerular mesangial cells in rat Thy-1 nephritis through TRAF6-mediated PI3K-dependent Akt1 activation. J Pathol 226: 619-632, 2012.

28. Tang H, Amara U, Tang D, Barnes MA, McDonald C and Nagy LE: Synergistic interaction between C5a and NOD2 signaling in the regulation of chemokine expression in RAW 264.7 macrophages. Adv Biosci Biotechnol 4: 30-37, 2013.

29. Curci C,Castellano G, Stasi A, et al: Endothelial-to-mesenchymal transition and renal fibrosis in ischaemia/reperfusion injury are mediated by complement anaphylatoxins and Akt pathway. Nephrol Dial Transplant 29: 799-808, 2014.

30. Byler S, Goldgar S, Heerboth S, et al: Genetic and epigenetic aspects of breast cancer progression and therapy. Anticancer Res 34: 1071-1077, 2014.

31. Faria JA, Correa NC, de Andrade C, et al: SET domaincontaining protein 4 (SETD4) is a newly identified cytosolic and nuclear lysine methyltransferase involved in breast cancer cell proliferation. J Cancer Sci Ther 5: 58-65, 2013.

32. Pei R, Wang P, Zhou Y, et al: Association of BRCA1 K1183R polymorphism with survival in BRCA1/2-negative Chinese familial breast cancer. Clin Lab 60: 47-53, 2014.

33. Unnewehr H, Rittirsch D, Sarma JV, et al: Changes and regulation of the C5a receptor on neutrophils during septic shock in humans. J Immunol 190: 4215-4225, 2013.

34. Liu L, Zhang Y, Duan X, et al: C3a, C5a renal expression and their receptors are correlated to severity of $\operatorname{IgA}$ nephropathy. J Clin Immunol 34: 224-232, 2014.

35. Müller MC, Stroo I, Wouters D, et al: The effect of C1-inhibitor in a murine model of transfusion-related acute lung injury. Vox Sang 107: 71-75, 2014.

36. Qin L, Ren Y, Chen AM, et al: Peroxisome proliferator-activated receptor $\gamma$ ligands inhibit VEGF-mediated vasculogenic mimicry of prostate cancer through the AKT signaling pathway. Mol Med Rep 10: 276-282, 2014.

37. Singel SM, Cornelius C, Zaganjor E, et al: KIF14 promotes AKT phosphorylation and contributes to chemoresistance in triplenegative breast cancer. Neoplasia 16: 247-256, 2014. 